\title{
The Economist's Dilemma-The Relevance of Development Economics to Public Administration
}

\section{S. Edmonds}

Teaching development economics and development planning to 'generalist' administrators, as one component in a multi-disciplinary approach to courses in public administraion, requires the continuous questioning of much of economics as traditionally taught in institutions in the West. How relevant are theories developed out of experience in rich countries to administrators in poor countries, and what are their practical relevance to the problems facing the poor countries today?

Many course participants have little, if any, formal grounding in economics, and what they have is likely to be transferred Western theories of 20 or more years ago. They find it difficult to relate practical experience in their own countries with the uncertain theories and mixture of imperfect strategies and value judgements that play such a major part in development economics today. They hope to return to their work situations with a complete package of applicable solutions, or at least an emergency tool kit. At times it seems that all they will receive is a hotch potch of quantitative techniques and theories; mixed with indiscriminate borrowings from a range of disciplines, such as management, sociology, political science and behavioural studies, and flavoured with a number of largely unrelated and often conflicting strategies. The growing consensus amongst development economists is that an alternative can only emerge out of their own traditions and experiences (Hunter, 1974), and the advice to "do what you can" until this day arrives fills them with dismay and anger (Caiden and Wildavsky, 1974:25). Is this the best that the developed countries can offer, and is it worth travelling this far to hear?

Discussions arising out of the courses suggest that there is a considerable gap in the understanding of the issues involved, and their implications, between Western students of development economics and administrators engaged in day-to-day implementation of policy in poor countries.

There are also wide differences in the circumstances of the countries represented on courses, and in individual administrators' perceptions of the economic and social problems facing them. Many of them have never had the opportunity to look beyond the immediate demands of their responsibilities, and have initial difficulty in dis- cussing wider issues. There is, however, a large area of common understanding, of lessons to be learnt from each other's experience, and a degree of support and increased confidence to be gained from the knowledge that the difficulties encountered are not unique. In recent years also, there has been an awareness that the developing countries as a group have common interests in certain areas in their relationships with the rich countries.

Faced with the need to relate the teaching of economics to the needs of administrators, one possible course of action is to attempt to escape into the more rarified areas of quantitative theory; to emphasise the collection and classification of data; the identification and study of indicators of economic and social growth and the preparation of models, not as a means of simplification but in order to avoid the criticism of irrelevance, superficiality and lack of academic respectability. The relationship between the teacher and the student becomes clear-cut, a familiar situation to those educated in more formal systems. Generalist administrators, often poorly equipped in both theory and numeracy, can obtain few insights into economic circumstances in their own societies from the greater part of the present flood of economic writings, which tend to use a degree of quantification and an obscurity of language guaranteed to mask any practical implications. At times one is forced to act as a mere interpreter, translating the more valuable material and putting it into a package related to the needs of the study fellows. Equally bewildering for many, brought up to accept academic disciplines as water-tight compartments, is the growing number of disciplines contributing to development economics and development studies, each bringing with it its own language and concepts.

The alternative is to try to develop a coherent area of study from the "large doses of casual empiricism, fairly 'unrigorous' theorising and eclectric approach to related social studies" (Lall, 1976 : 181) that makes up development economics. To do this it is necessary to take into account the growing value of interdisciplinary studies, often critical of the ideological basis and accompanying value judgements associated with development economics as derived from the his- 
torical experience of economic growth within a capitalist framework. Much of this literature argues that the overthrow of existing political and social institutions is an essential prerequisite to the successful tapping of the potential for change and growth in the poor countries. A very strong influence has been the concept of underdevelopment and dependency originally derived from Latin American experience and emphasising the strong and complex nature of the relationships between 'metropolitan' and 'peripheral' states as an explanation of the continuing failure of attempts at economic and social development in poor countries economically and culturally dominated by rich countries (Lall, 1975).

At the same time there has been a growing crisis of confidence amongst economists and planners as the results of two decades of advice on the initiation and maintenance of economic growth are being evaluated (Healey, 1972). The initial assumption that 'take off' into sustained economic growth and access to the consumption patterns of the rich countries would be a relatively painless and simple process requiring little more than the transfer of modern technology and a flow of resources to the developing countries was shaken by the experience of the 1950 s and early 1960s, and the generally disappointing record in most developing countries.

Attention was then directed to the identification of obstacles to the successful implementation of strategies for growth, such as the commitment of politicians, elites and bureaucracy to the implementation of planning and economic growth and the lack of sufficient administrative capacity to implement these policies. This concern included areas well outside the boundaries of economics as normally defined, although clearly within public administration itself, and it was, for example, possible to study administrative reform and the improvement of administrative capacity as part of examination of implementation of economic policy and planning. It became increasingly impossible to ignore the political, social and institutional environments in the poor countries and the need for economic development and planning to come to terms with these environments (Rothstein, 1976; Killick, 1976).

At the same time concern was directed at the consequences of successful economic growth and its effects on the distribution of incomes within society. In some cases the political and social stresses resulting from growing inequalities in income distribution caused sufficient political instability to negate the greater part of the growth achieved. The concept of growth was widened to include nearly every form of activity within the poor countries, and attention was focused on the way in which the cake was sliced, rather than whether the cake itself could be made larger. The small band of poor countries which broke through the barrier of poverty found themselves facing problems of even greater complexity as a consequence of their success, such as spectacular increases in the growth of population as a result of improvements in health care and sanitation, or rapid urbanisation as a response of agrarian society to modernisation (Friedman, 1972: 13).

Under these circumstances it has becme more difficult to provide a coherent and rational account of the development process. Not all this intellectual pilgrim's progress is shared by administrators from the developing world, indeed they often find themselves drowning under the flood of competing ideologies and conflicting theories. In the search for a tangible area which can be taught as an identifiable subject with an adequate theoretical base and practical applications one is forced at times to agree that the "Development economist must be defined as one who has accepted the inevitability of a number of departures from the basic premises of neo-classical economics and is thus forced to operate in the ill-defined world of the second best" (Chenery, 1975).

Yet certain issues still appear to be basic to a course of development economics; the key role of capital accumulation, however defined, in the development process; the need for a rational basis for resource allocation and, perhaps most importantly, a capacity to analyse development issues critically. Under the present circumstances there is a very real danger that the overall approach may become destructively negative and over-critical, with the consequence that administrators may return home less able to seek solutions within the existing framework; it is both unrealistic and dangerous to expect them to be able to change this framework radically.

On economic planning one is on firmer ground; there is a clearly established armoury of skills and techniques exported from the rich to the poorer countries, and practised with varying degrees of commitment and success by nearly all poor countries. Planning reached its zenith in the 1960s, but with hindsight it never achieved the results claimed by its strongest supporters, although there has been a recent tendency to ignore the real achievements in many countries, and the very great progress made in modernising institutions and the economy. Considering the limited amount of experience of sustained attempts at maintaining economic growth, the pro- 
gress made was substantial. The planning failures were catalogued in depressing detail by Waterston in 1965 and subsequently substantiated in a number of books and articles with titles such as 'The Crisis in Planning' (Faber and Seers, 1972) and 'Destructive Decision Making in Developing Countries-broken promises and false premises' (Gross, 1974).

The planners, like the economists, often sought refuge from the obvious gap between the intentions of planning and the consequences by preparing ever more elaborate plans, making increasing demands on the very resources in shortest supply in a poor country, rational behaviour and commitment by elites, skilled administrators, etc., to the extent that Chapter 9 in Caiden and Wildavsky's book Planning and Budgeting in Poor Countries is called 'Planning is not the solution, it is part of the problem' (Caiden and Wildavsky, 1974:264). As implementation lagged, the planners blamed everyone but themselves, accusing the politicians of irrationality and lack of commitment and the administrators of lack of capacity and skill. They confused the meansrapid economic growth through planning-with the ends, and demanded increased power and resources if planning was to succeed. The literature of the late 1960s is full of discussion on the correct siting of the planning unit and its relationship to the policy-makers and bureaucracy, and in particular with the Ministry of Finance. (Caiden and Wildavsky describe the struggle between the planners and the Ministry of Finance and the almost certain victory of the Ministry with its control of the annual budgetary process.)

A further step in the evolution of development economics has been the interest in the concept of self-reliance and the need for the poor countries to produce policies aimed at the eventual development of societies with an equitable distribution of income and 'reasonable' standard of life compatible with their own resources, traditions and beliefs rather than based on the rich metropolitan capitalist countries. This concept, although still relatively ill-defined, appeals to many of the critics of present development policies, although often for a variety of reasons. There would appear to be two quite different definitions of selfreliance, one being a policy of seeking economic and social development but through one's own efforts and sacrifices, the other being a willingness to accept near-stagnation in terms of economic growth, with an emphasis on an equitable society with a high level of social services, etc. The first approach is based on the assumption that a poor country cannot break out of poverty within the existing environment and can only provide the basis for sustained growth through a period of isolation requiring considerable sacrifice. The experience of China and possibly Cuba and Tanzania is felt to be most relevant. The alternative, of an acceptance of limited growth with a concentration on a more equitable distribution of wealth, has not been so clearly expressed, although Sri Lanka would appear to be a representative example. The contradictions implicit in a policy of self-reliance have been discussed (Rothstein, 1976).

An alternative, if at present unlikely, policy would be a deliberate redistribution of wealth between the rich and poor countries. The basis for such a policy is becoming clearer through the meetings of UNCTAD, the North South dialogue, and the concept of a new international economic order. The issues raised in these discussions do not yet appear to be of general interest in the developing countries and many study fellows find it difficult to appreciate the implications of the proposals.

The economists and planners no longer enjoy the monopoly of development studies that was their's in the 1950s and for much of the 1960s, when they were able to consider themselves separate from the mainstream of public administrators. With the growth of multi-disciplinary studies and a greater understanding of the importance of non-economic factors in the development process it would seem that development economics is now one of a number of strands that go to make up public administration, neither more nor less important than the other disciplines involved. Whilst public administration finds it difficult to justify its existence as a separate and distinct discipline, it clearly provides a framework within which a wide range of subjects, including economics and in particular development economics and planning, can be combined in a study of the development process in poor countries. Over time the subjects involved will change, and so will the relative importance of the various contributions, but economics will always have a valuable and relevant contribution to make.

\section{References}

Caiden \& Wildavsky, 1974, Planning and Budgeting in Poor Countries, John Wiley \& Sons, New York

Chenery, H. B., 1975, Review of Paul Streeton: Frontiers of Development Studies, Journal of Economic Literature, March 
Faber, M. \& Seers, D., 1972, The Crisis in Planing, Chatto \& Windus (for Sussex University Press), London

Friedman, I., 1973, Dilemmas of the Developing Countries - the Sword of Damocles, Finance and Development, March

Gross, B., 1974, Destructive Decision Making in Developing Countries, Policy Sciences, June

Healey, D., 1972, Development Policy-New Thinking about an Interpretation, Journal of Economic Literature, September 10

Hunter, Guy, 1974, Indigenous Development and the Developing World, ODI Review 2

Killick, T., 1976, The Possibilities of Development Planning, Oxford Economic Papers, July
Lall, Sanjaya, 1976, Conflicts of Concepts: Welfare Economics and Developing Countries, World Development, March

Lall, Sanjaya, 1975, Is 'Dependence' a useful concept in analysing underdevelopment?, World Development, November

Rothstein, R., 1976, Politics and Policy Making in the Third World: Does a Reform Strategy Make Sense? World Development, July

Rothstein, R., 1976, The Political Economy of Redistribution and Self Reliance, World Development, July

Waterston, A., 1965, Development Planning: Lessons of Experience, Johns Hopkins, Baltimore 